\section{Early Treatment Protocol for Skeletal Class III Malocclusion}

Paula Vanessa Pedron Oltramari-Navarro ${ }^{1}$, Renato Rodrigues de Almeida ${ }^{1}$, Ana Cláudia de Castro Ferreira Conti ${ }^{1}$, Ricardo de Lima Navarro², Marcio Rodrigues de Almeida', Leandra Sant'Anna Ferreira Parron Fernandes' ${ }^{1}$

Skeletal Class 111 malocclusion, with its unpredictable and unfavorable nature, has been characterized by a growth pattern with doubtful prognosis regarding orthodontic mechanics, even when performed early. For a long time, Class 111 malocclusion was regarded as a synonym of mandibular prognathism, regardless of the affected skeletal structures. Mandibular growth, essentially determined by genetic factors, could barely be controlled by early orthodontic interventions. Therefore, the treatment choice was to wait for the patient to grow, and then make an orthodontic intervention associated with an orthognathic surgery. Maxillary involvement in the etiology of Class 111 malocclusion was conclusive to change orthodontic therapeutics. Maxillary intramembranous growth has a better response to orthopedic treatment, based on growth control and redirection, thus contributing for early intervention success. In several cases, excellent results have been achieved with rapid maxillary expansion and protraction. The aim of this study was to describe and discuss the treatment of a patient with Class 111 malocclusion, whose treatment planning comprised two phases: interceptive (mechanical orthopedic appliances) and comprehensive (fixed orthodontic appliance). The results of this case showed that Class 111 malocclusion should be intercepted as early as possible to permit growth redirection, mainly when the maxilla is the primary etiologic factor or dental and/or functional factors are involved. Diagnosis, treatment planning and prognosis depend on patient age, growth potential and severity of malocclusion. Early intervention, adequate indication of appliances, and patient compliance are key factors for good outcomes.

\author{
'Department of Orthodontics, \\ UNOPAR - University of North \\ Paraná, Londrina, PR, Brazil \\ ${ }^{2}$ Department of Dentistry, Area of Oral \\ and Maxillofacial Surgery, Graduate \\ Program, UNESP - State University \\ of Maringá, Maringá, PR, Brazil
}

Correspondence: Profa. Dra. Paula Vanessa Pedron Oltramari-Navarro, Rua Paranaguá, 803, ap. 92, Centro, 86020-030 Londrina, PR, Brasil. Tel: +55-43-3371-7991. e-mail: pvoltramari@hotmail.com

Key Words: orthodontic interceptive, malocclusion, Angle Class III, palatal expansion technique.

\section{Introduction}

Noticeable characteristics of Class III malocclusion result in unpleasant aesthetics for a child, and consequently lead parents to seek for orthodontic treatment at an early age. The negative dentoskeletal discrepancy between the apical bases, at the sagittal dimension, is mainly verified by a concave profile caused by deficiency of the facial middle third, absence of a zygomatic prominence and excess of the facial lower third. These features can also be accompanied by maxillary atresia, lower lip protrusion, and/or an anterior crossbite $(1,2)$.

This malocclusion has been characterized by skeletal, functional, and dental discrepancies, which may or may not be associated with each other. In the facial evaluation, mandibular prognathism, maxillary retrognathism or both can be observed, characterizing a skeletal Class III malocclusion $(3,4)$. Maxilla and mandible may assume different relationships in sagittal and vertical directions. Maxillary deficiency has been regarded as the primary etiologic factor of this malocclusion development, and also a decisive feature for a good prognosis (5-7).

Considering the functional aspect, the presence of an anterior crossbite may be observed as a result of a mandibular forward displacement, due to abnormal occlusal contact. In cases of tooth crossbite, an axial inclination involvement of the maxillary and/or mandibular teeth can be observed (3). Consequently, in a dental or functional crossbite without skeletal involvement, the diagnosis and treatment should also receive special attention, to avoid skeletal structure implications (8).

After skeletal disharmony is confirmed, a differential clinical diagnosis of Class III malocclusion should be made, and the occlusal pattern both at Centric Relation (CR) and Intercuspal Position (IP) should be verified (Fig. 1). This evaluation affords the severity of the malocclusion, and distingushes the functional (caused by a mandibular forward displacement) from a skeletal or dental Class III malocclusion. Lateral cephalograms, at the aforementioned occlusal positions, confirm this diagnosis (Fig. 1) $(3,9)$. Other relevant aspects concerning the diagnosis should also be taken into account, such as: family history, growth potential and pattern, in addition to the patient's age $(3,10)$. A thorough evaluation in transversal, sagittal, and vertical directions is essential.

Considering a skeletal Class III malocclusion, the greater the maxillary involvement at the expense of participation of the mandible, the better the prognosis. In this condition, the orthopedic treatment to be performed aims at redirecting patient growth by applying forces on sutural surfaces. This treatment protocol results in forward displacement of the maxilla and in bone apposition. Accordingly, significant sagittal changes are induced, thus allowing a non-surgical 
correction of the malocclusion in several cases $(6,11-13)$. The observation of clinical reports $(5,13)$ has indicated the advantages of an early treatment, performed at early mixed dentition. It is important to note that, in order to achieve a good outcome, the treatment should be started before the pubertal growth spurt, taking great advantage of its potential. Furthermore, it should be taken into account that the end of the maxilla growth preceeds the growth of the mandible.

The aim of this study was to describe and discuss the treatment of a patient with Class III malocclusion, whose treatment protocol comprised two phases: interceptive (mechanical orthopedic appliances) and comprehensive (fixed orthodontic appliance).

\section{Case Report}

Diagnosis and Etiology

A nine-year-and-10-month-old female patient sought orthodontic treatment with chief complaint of an anterior crossbite. During the anamnesis, a good general health condition was observed without deleterious oral habits. Facial evaluation showed lack of middle third development (Fig. 1A and 1B). In the intraoral examination, at IP (Fig. 1C), the patient showed anterior mandibular displacement, mesial relationship of the primary molar and canines and an anterior crossbite, thus characterizing a Class III malocclusion.

At $C R$, an edge-to-edge incisor relationship was observed, which improved the prognosis (Fig. 1D).

Radiographic examination was performed aiming to complement the clinical examination for establish the diagnosis. A panoramic radiograph showed the presence of all permanent teeth either already erupted or at the several stages of formation, in mixed dentition.

The lateral cephalogram evaluation at IP afforded detection of a Class III malocclusion and an acute ANB angle. In cases where the mandible has an anterior deviation, it is essential to take a lateral cephalogram at $\mathrm{CR}$, so that the low severity of the malocclusion may be ascertained and greatly favor treatment prospects.

\section{Treatment Options and Expected Results}

There are several appliances for early treatment of skeletal Class III, such as, Bionator (14), Frankel (FR-III) (15), chincup (16,17), Reverse Twin-Block (RTB) $(18,19)$, Eschler appliance ("progenic appliance") (16) and protraction face mask treatment (20). These appliances treatment results depend on patient's compliance. Initially, the Eschler's
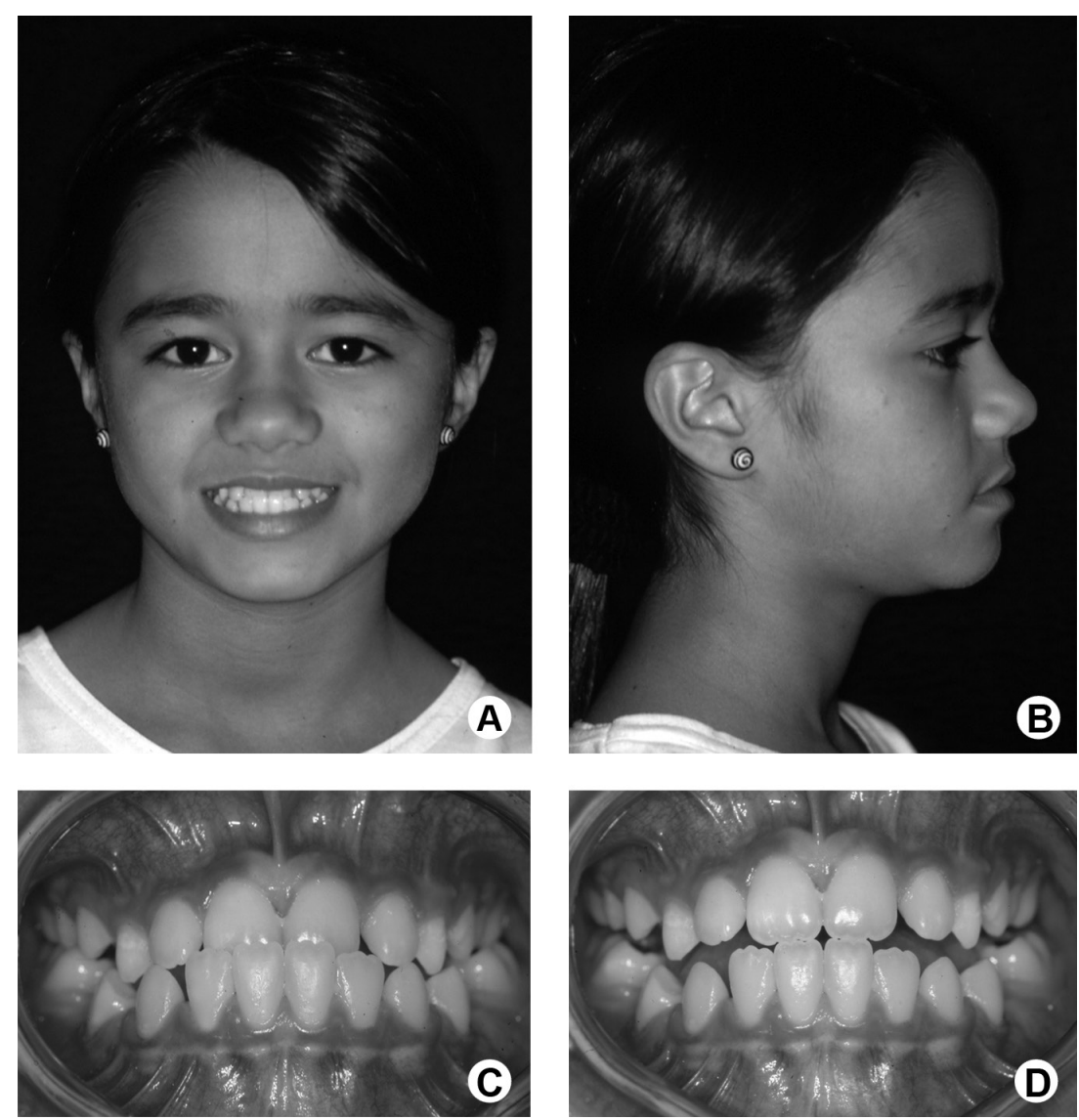

Figure 1. A and B: Initial extraoral photographs. C: Initial intraoral photographs at intercuspal position. D: Centric relation. 
appliance was chosen in this case, followed by the facemask protocol considering the maxillary deficiency compounding the Class III malocclusion (20).

\section{Case Description}

In this clinical case, the treatment protocol comprised two phases: an interceptive phase and a comprehensive phase.

The interceptive phase started immediately after the clinical and radiographic evaluation, with a removable orthopedic appliance: Eschler's appliance, the so-called "Progenic Appliance". This appliance is composed of: a)
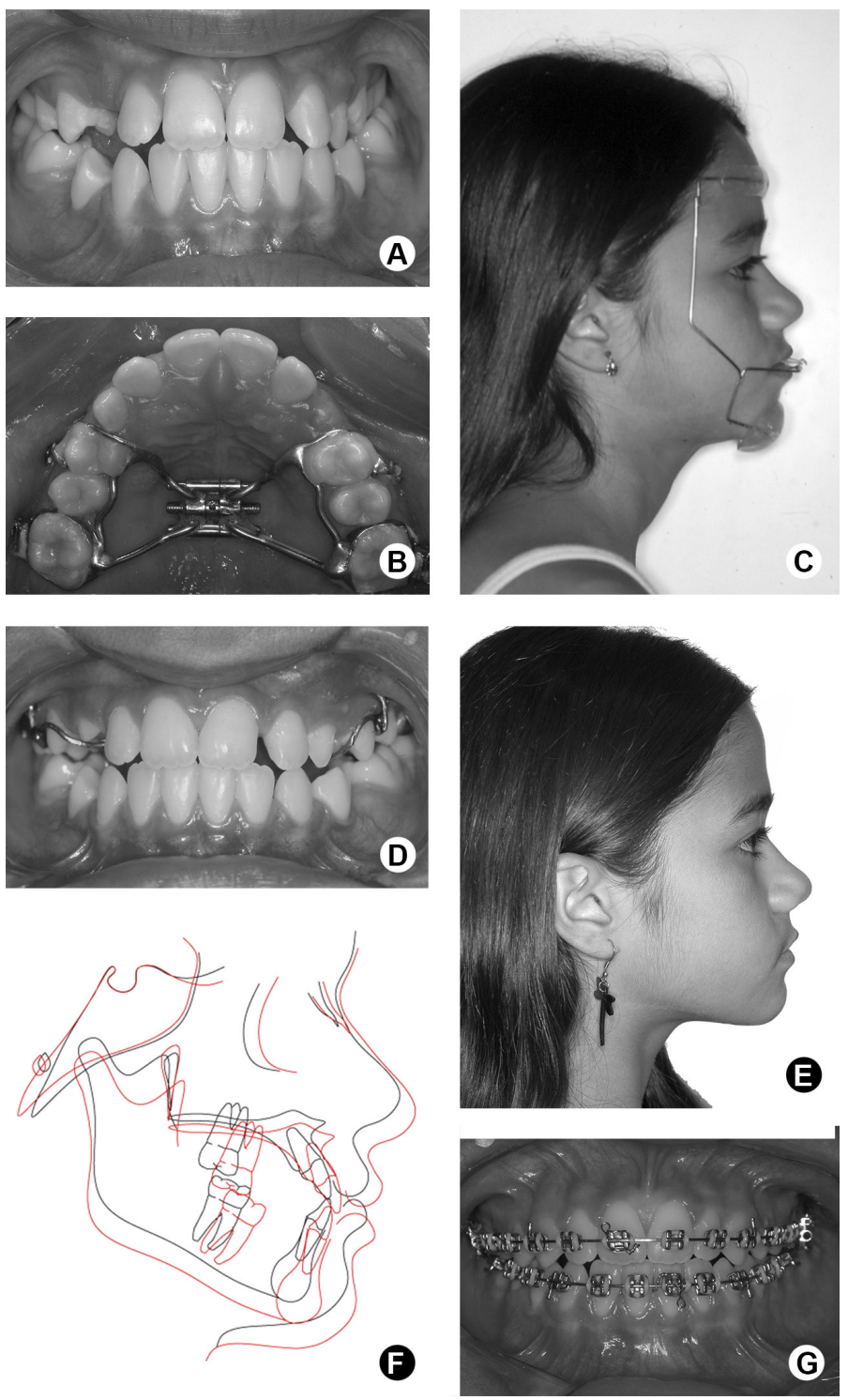

Figure 2. A: Intraoral photographs showing pre-expansion aspect. B: Hyrax-type expander. C: Extraoral photograph showing the maxillary protraction face mask. D: Intraoral photograph previous to the reverse traction of the maxilla. E: Extraoral aspect after the active phase of the maxillary protraction. F: Superimposition of the lateral cephalogram tracings at the beginning of the treatment (black) and after the reverse traction of the maxilla (red). G: Intraoral photograph showing the comprehensive phase. retention clasps, e.g. Adams clasp for molars, and intermolar auxiliary clasps for deciduous teeth and premolars, b) Eschler's labial bow, made in 0.9-mm stainless steel wire and adapted at the labial surface of the lower incisors, c) occlusal lifting in acrylic resin with a thickness of about 2 to $3 \mathrm{~mm}$. If necessary, springs can be added to correct the anterior crossbite, and an expander screw, to correct the posterior crossbite.

The patient used the appliance for 10 months, with poor compliance, especially regarding the expander screw activation. Notwithstanding, significant improvement of the anterior crossbite was observed at IP (Fig. 2A). However, an adequate correction of the posterior crossbite and improvement of the facial profile were still necessary.

Accordingly, rapid maxillary expansion (RME) was performed, followed by maxillary protraction $(2,4,5,9,10,13,14)$. Besides correcting the posterior crossbite, RME stimulates sutural cellular activity, enhancing protraction results $(3,6,15)$. This can be performed by using a Hyrax-type expander, composed of buccal hooks soldered onto the appliance to receive the protraction elastics (Fig. $2 \mathrm{~B}$ and $2 \mathrm{D}$ ). The expander screw was activated following Haas' protocol (1961), and consisted of one full turn (4/4 - $1 \mathrm{~mm})$ just after the appliance installation, followed by daily activations of $2 / 4$ turn $(1 / 4$ in the morning and $1 / 4$ in the evening $-1 / 2 \mathrm{~mm}$ ), which lasted for some 2 weeks. On the $14^{\text {th }}$ day of activation, a facemask for maxillary protraction was installed (Fig. 2C).

Maxillary protraction was carried out during the active phase of RME, and the face mask was used during 14 hours per day. A large array of extraoral appliances for maxillary protraction is available. In this case, Turley's face mask was chosen, which requires an impression of the patient's face with alginate. Then a cast of the patient's face was obtained at a laboratory to build an individual appliance. Half-inch (1/2") elastics were applied, and changed every two days, with forces of 500 $g$, on each side.

After 8 months of active treatment, the overjet was overcorrected, and the face mask was only used as a night retention appliance. In this phase, aiming at increasing the patient's comfort, the expander appliance was changed to a fixed palatal bar, extending up to the premolars, on both sides. Thus, retention was maintained in the arch posterior area, allowing the use of the face mask for other 8 months. Additionally, a Nance lingual arch was installed on the lower arch as a space maintainer, 
and kept until the complete development of permanent dentition.

After the use of the maxillary protraction mask (Fig. $2 \mathrm{E}$ and $2 \mathrm{~F}$ ), an anterior displacement of the maxilla was verified due to the increase of SNA and NperpA. Also, a mandibular clockwise rotation was obtained, attested by an increase of SNGoGN and a reduction of SNB, both contributing to increase facial convexity (ANB, NAP), and to improve the facial profile.

The comprehensive phase started after completion of the interceptive phase, and was carried out when the dental arches were at the stage of complete permanent dentition. This stage aimed at treatment finalization. Thus, the arches were both aligned and leveled (Fig. 2G), followed by the use of: Class III elastics on the right side; Class II elastics on the left side; and two elastics crossed in the anterior area, in order to distribute the forces to correct the dental midline. A quarter-of-an-inch (1/4") diameter elastics were used in this phase, and changed every three days.

After 20 months of comprehensive treatment, a satisfactory functional occlusion was achieved, and the facial profile obtained in the interceptive phase was maintained (Fig. 3A-3C). Initial and final cephalometric measurements, at IP, also demonstrated good treatment outcomes (Table 1).

Three years after the end of comprehensive treatment, the 17-year-old patient came to a follow-up appointment, and stability of the results was ascertained (Fig. 3D-3F).
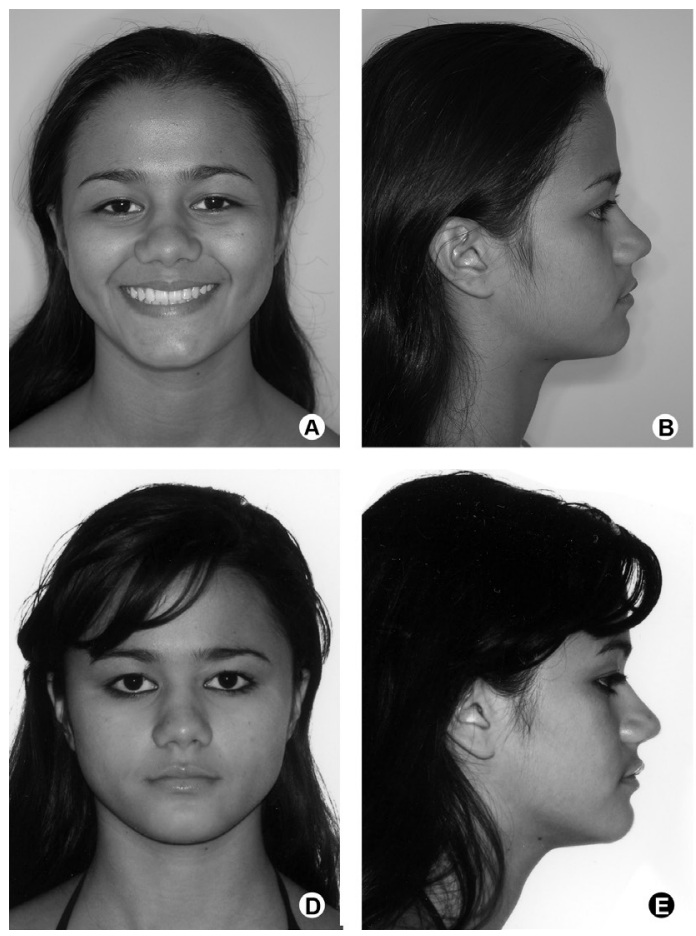

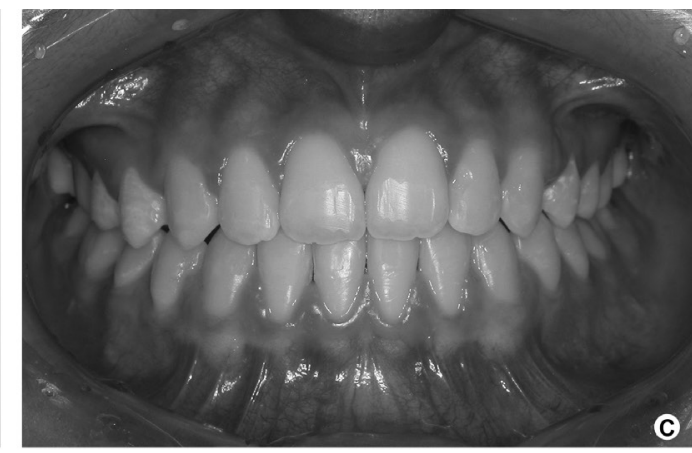

\section{Discussion}

Although moststudies have been based on cephalometric values, which are insufficient to define reliable normality methods and parameters, it is possible to state that real mandibular prognathism is less frequent than originally thought. Consequently, Class III therapy and treatment prognosis become more favorable (6).

Cephalometric values should be carefully analyzed, since Class III malocclusion patients have an acute cranial base angle and lower cranial base length. Also, a more posterior $N$ point is observed. Accordingly, the measurements using the cranial base as reference (SNA, Nperp-A, SNB, Nperp-B) cannot be evaluated individually. Ideally, the real length of both the maxilla and mandible should be assessed (Co-A, Co-Gn), at each age (20).

Additionally, the use of normative patterns of one agegroup for subjects at another age-group may negatively affect diagnosis and treatment planning (10). Therefore, when only SNA and SNB measurements are used, the mandible is considered as the main contributing factor for the malocclusion (6).

In Class III patients, a lateral cephalogram at CR is extremely important for the diagnosis, because it shows real maxillary and mandibular involvement. When a lateral cephalogram, taken at CR, is observed (Fig. 1F), good possibilities of success of the treatment can be verified due to the edge-to-edge relationship of the incisors. This was observed in the present study, since the cephalometric

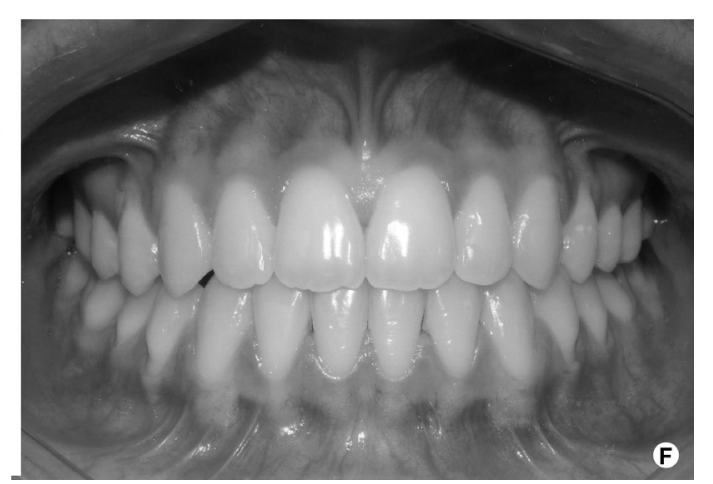

Figure 3. Final extraoral (A and B) and intraoral (C) aspects. Three-year post-treatment follow-up: extraoral (D and E) and intraoral photographs (F). 
measurements at CR demonstrated real maxillary and mandibular participation (Table 1). Consequently, the prognosis improved, when compared with that evaluated with the use of a lateral cephalogram at IP (Fig. 1E), which had shown greater mandibular involvement (3).

In the facial analysis, the patient showed an anterior shift of the mandible, with ANB and NAP involvement, which contributed to form a concave facial profile. The NPerp-P value confirmed this finding, and the reduced ALFH reinforced the appearance of protrusion. SNGoGn and SNGn angles confirmed the anterior lower mandibular growth. Co-A and Co-Gn values showed the maxilla in a more retrusive condition (Table 1).

This cephalometric analysis allowed establishing the treatment protocol comprising maxillary expansion and protraction. The lateral cephalogram image showed the proportion of maxillary involvement in the Class III malocclusion, thus affording a good prognosis $(3,6)$.

Following the maxillary expansion and protraction, the initial (Fig. 1E) and post-protraction (Fig. 2G) lateral cephalograms at IP were superimposed, and centered at SN. Improvement of the post-protraction measurements could be clearly noted (Table 1). The changes of the ANB and NAP values resulted in a better profile, and in a more anterior position of point $A$, also confirmed by the positive value of Nperp-A. The increase of ALFH reduced the appearance of mandibular prognathism, and the changes in $\mathrm{SN}-\mathrm{GoGN}_{\text {, }}$ $\mathrm{SN}-\mathrm{Gn}$ and $\mathrm{Co}-\mathrm{A}$ values confirmed growth redirection.

The changes normally observed after maxillary expansion and protraction have been the anterior displacement of the maxilla, with an increase of the SNA angle, and an improvement of Nperp-A. This was possible due to the anterior shift of point $A$, and to the mandibular clockwise rotation, with retropositioning of point $B(11,21)$.

The counterclockwise rotation of the maxilla occurs due to the palatine plane rotation in relation to the cranial base, which contributes to increase the facial convexity and profile improvement (ANB-NAP). Additionally, a backward and downward rotation of the mandible occurs, resulting in changes of the SNGn and ALFH values. Considering the ALFH values, patients with increased facial height previous to the maxillary disjunction will very likely show a more evident value. The magnitude, duration, and direction of the protraction significantly influence the rotation center of the maxilla. It has been recommended that the protraction force be horizontal, parallel to the occlusal plane, or slightly directed downward and forward, resulting in an angle of $20^{\circ}$ to $30^{\circ}$ in relation to the occlusal plane. As a result, the effect of the palatine plane rotation is reduced $(7,12,17,18)$. The retroclination of the mandibular incisors

Table 1. Comparison of pre- and post-expansion/protraction measurements

\begin{tabular}{|c|c|c|c|c|c|}
\hline $\begin{array}{l}\text { Cephalometric } \\
\text { variables }\end{array}$ & $\begin{array}{c}\text { Pattern value } \\
10 \text { years }\end{array}$ & $\begin{array}{c}\text { Initial } \\
\text { (Centric relation) }\end{array}$ & $\begin{array}{l}\text { Initial (Intercuspal } \\
\text { position) }\end{array}$ & $\begin{array}{l}\text { Post-expansion/Protraction } \\
\text { (Intercuspal position) }\end{array}$ & $\begin{array}{c}\text { Pattern value } \\
12 \text { years }\end{array}$ \\
\hline SNA ( $\left.{ }^{\circ}\right)$ & 81.5 & 87.8 & 88.0 & 90.8 & 81.1 \\
\hline SNB ( $\left.{ }^{\circ}\right)$ & 78.2 & 88.3 & 90.1 & 88.9 & 78.9 \\
\hline ANB $\left({ }^{\circ}\right)$ & 3.3 & -0.5 & -2.1 & 2.0 & 2.2 \\
\hline $\operatorname{NAP}\left({ }^{\circ}\right)$ & 6.1 & 0.0 & -3.4 & 1.2 & 2.5 \\
\hline SN.GoGn ( $\left.{ }^{\circ}\right)$ & 34.1 & 26.5 & 24.5 & 23.1 & 33.2 \\
\hline SN.Gn ( $\left.{ }^{\circ}\right)$ & 77.3 & 61.4 & 59.3 & 61.0 & 78.5 \\
\hline Co-A (mm) & 83.9 & 74.5 & 72.1 & 77.9 & 86.9 \\
\hline Co-Gn (mm) & 106.4 & 102.1 & 99.2 & 106.0 & 113.7 \\
\hline Nperp-A (mm) & -1.3 & 1.1 & 0.3 & 5.9 & -1.1 \\
\hline Nperp-P (mm) & -7.9 & 2.3 & 3.2 & 9.2 & -4.5 \\
\hline 1.NA ( $\left.{ }^{\circ}\right)$ & 24.2 & 28.9 & 32.5 & 20.7 & 26.1 \\
\hline 1-NA (mm) & 3.7 & 4.4 & 5.3 & 3.1 & 4.6 \\
\hline $1 . \mathrm{NB}\left({ }^{\circ}\right)$ & 27.6 & 24.6 & 23.9 & 17.0 & 26.8 \\
\hline $1-\mathrm{NB}(\mathrm{mm})$ & 4.7 & 4.0 & 4.1 & 2.8 & 4.7 \\
\hline ALFH $(\mathrm{mm})$ & 61.9 & 56.1 & 53.0 & 57.9 & 64.2 \\
\hline IMPA ( $\left.{ }^{\circ}\right)$ & 92.5 & 86.8 & 86.7 & 81.2 & 92.4 \\
\hline Witts (mm) & - & -7.3 & -7.9 & -4.1 & - \\
\hline
\end{tabular}


increases, causing a decrease of the IMPA value (11-13,22).

The use of an Eschler appliance prior to the maxillary expansion and protraction contributes for a proclination of the maxillary incisors. After it is used, even with patient's poor compliance, an almost total correction of the anterior crossbite at IP can be observed.

Concerning the decision of whether or not to expand the maxillary arch previous to the facial mask protraction, a study conducted by Vaughn et al. (7) seems important, in that it showed similar results, between the two treatment protocols used, leading to the conclusion that the maxillary expansion did not influence the results obtained (7). On the other hand, more recent studies performed by Gautam et al. $(21,23)$ emphasized the need for expansion previous to protraction. These authors observed a greater displacement of the craniofacial structures when the expansion was performed previously. Consequently, the treatment outcome was more effective due to the greater tension on the sutural areas, which offers a favorable cellular response. Maxillary protraction would then be directly related to the force or tension application on the sutural area, in that it promoted disarticulation, and rendered the forward displacement of the maxilla easier. Another result is bone growth due to bone apposition $(4,6,11,12,21,23)$.

Nevertheless, a consensus prevails on the requirement of rapid maxillary expansion previous to reverse traction, when the patient shows upper dental arch atresia or a posterior crossbite $(6,7,11,12,21)$.

Moreover, it is important to emphasize that the earlier the intervention, the better the results obtained $(3,5,12)$. The psychosocial factor is also relevant $(12)$. Normally, children show discomfort regarding their facial appearance caused by Class III malocclusion, and face problems due to the esthetic involvement. Depending on the severity of the case, an early intervention affords the child's proper social insertion, without embarrassment or psychological involvement. Franchi et al. (24) concluded that early treatment was more effective to control a Class III malocclusion when it had been started at the initial phase of the dentition development (end of primary dentition, or beginning of mixed dentition). This has allowed efficiency as to maxilla advancement and restriction as to mandibular growth, as well as correction of the occlusal relationship. Patients treated in the final phase of mixed dentition also showed improvements with the maxillary expansion and protraction treatment, despite their lower results. Early treatment produces significant post-pubertal changes, both on the maxilla and the mandible, while a late treatment only induces a significant restriction of mandibular growth. Regardless of the time of treatment, correction of the occlusal relations of Class III malocclusion patients, treated with rapid maxillary expansion and protraction, followed by fixed appliances seems to produce bone adaptations instead of dentoalveolar movements. Another advantage of an early treatment is that if the patient did not reach a satisfactory outcome during the first maxillary expansion and protraction, in the pre-pubertal period, a secondary intervention with this same protocol could be performed aiming to inhibit mandibular projection (24).

The interceptive approaches of the Class III malocclusion could be performed with different appliances, including fixed and removable ones, removable functional appliances, chincup, protraction headgear, and skeletal anchorage systems $(14,15,17,20,25)$. The protocol to be chosen is less important since all appliances seemed to be effective; the most important issue is related to long-term stability of this treatment, which relies on the presence of continued favorable growth (19).

Even with early intervention, stability will depend on several factors, such as: maxillary and/or mandibular skeletal involvement, growth potential, age, family history, genetic influence, as well as patient compliance $(4,10)$. Therefore, treatment overcorrection has been recommended to compensate the negative factors.

In conclusion, Class III malocclusion should be intercepted early, aiming to redirect growth, mainly when the maxilla is the primary etiologic factor, or when dental and/or functional factors are involved. The diagnosis, treatment planning, and prognosis depend on several characteristics, which should be carefully analyzed by the orthodontist, such as: patient age, growth potential, and pattern. The earlier the intervention, the greater the chances of positive responses, regarding transversal maxillary advancement and increase. An adequate use of appliances, with correct application of intensity and direction, in addition to patient compliance are key elements for good outcomes.

\section{Resumo}

A má oclusão de Classe III esquelética, com sua imprevisibilidade e natureza potencialmente desfavoráveis, caracteriza um padrão de crescimento com duvidoso prognóstico à mecânica ortodôntica, ainda que esta seja realizada precocemente. Durante muito tempo, a Classe III foi considerada sinônimo de prognatismo mandibular, independente das estruturas esqueléticas comprometidas. 0 crescimento mandibular, determinado essencialmente por fatores genéticos, dificilmente seria controlado pela intervenção ortodôntica precoce. Assim, optava-se por aguardar o crescimento e então realizar a intervenção ortodôntica associada à cirurgia ortognática. A constatação de envolvimento da maxila como etiologia primária na má oclusão de Classe III foi decisiva para a mudança da terapêutica. 0 crescimento maxilar, de origem intramembranoso, responderia melhor ao tratamento por meio do controle e direcionamento do crescimento, contribuindo para o sucesso da intervenção precoce. Em muitos casos, excelentes resultados são obtidos com a expansão rápida e protração da maxila. 0 presente trabalho objetiva descrever e discutir o tratamento de uma paciente com má oclusão de Classe III, cujo plano de tratamento consistiu de duas fases: interceptora, realizada com aparelhos ortopédicos mecânicos e corretiva, com aparelho ortodôntico fixo. Os resultados 
deste caso clínico demonstraram que a má oclusão de Classe III deve ser interceptada o mais precoce possível, com vistas a redirecionar o crescimento. Esta abordagem deve acontecer, especialmente, quando a maxila é o fator etiológico primário ou quando fatores dentários e/ ou funcionais estiverem envolvidos na determinação desta má oclusão. 0 diagnóstico, o plano de tratamento e o prognóstico dependem da idade do paciente, do potencial de crescimento e da severidade da má oclusão. A intervenção precoce, a indicação de aparelhos adequados e a colaboração do paciente constituem fatores determinantes para a obtenção do sucesso desejado.

\section{References}

1. Staudt $C B$, Kiliaridis $S$. Different skeletal types underlying Class III malocclusion in a random population. Am J Orthod Dentofacial Orthop 2009;136:715-721.

2. Bergamo $A Z$, Andrucioli $M C$, Romano $F$, Ferreira JT, Matsumoto MA. Orthodontic-surgical treatment of Class III malocclusion with mandibular asymmetry. Braz Dent J 2011;22:151-156.

3. Cozzani G. Extraoral traction and class III treatment. Am J Orthod 1981:80:638-650.

4. McNamara Jr JA. An orthopedic approach of the treatment Class III malocclusion in young patients. J Clin Orthod 1987;21:598-608.

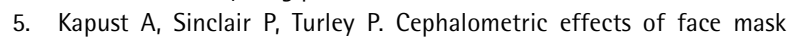
expansion therapy in class III children: a comparison of three age groups. Am J Orthod Dentofacial Orthop 1998;113:204-212.

6. Turley P. Orthopedic correction of Class III malocclusion with palatal expansion and custom protraction headgear. J Clin Orthod 1988;22:314-325.

7. Vaughn GA, Mason B, Moon HB, Turley PK. The effects of maxillary protraction therapy with or without rapid palatal expansion: a prospective, randomized clinical trial. Am J Orthod Dentofacial Orthop 2005; 128:299-309.

8. Hagg U, Tse A, Bendeus M, Rabie AB. A follow-up study of early treatment of pseudo Class III malocclusion. Angle Orthod 2004;74:465472.

9. Rabie $A B, G$ Y. Diagnostic criteria for pseudo-Class III malocclusion. Am J Orthod Dentofacial Orthop 2000;117:1-9.

10. Chen $F$, Terada $K$, Wu L, Saito I. Longitudinal evaluation of the intermaxillary relationship in Class III malocclusions. Angle Orthod 2006;76:955-961.

11. Gallagher $R$, Miranda F, Buschang P. Maxillary protraction: treatment and posttreatment effects. Am J Orthod Dentofacial Orthop 1998;113:612-619.
12. Saadia M, Torres E. Sagittal changes after maxillary protraction with expansion in class III patients in the primary, mixed, and late mixed dentitions: a longitudinal retrospective study. Am J Orthod Dentofacial Orthop 2000;117:669-680.

13. Yavuz I, Halicioglu K, Ceylan I. Face mask therapy effects in two skeletal maturation groups of female subjects with skeletal Class III malocclusions. Angle Orthod 2009;79:842-848.

14. Garattini G, Levrini L, Crozzoli P, Levrini A. Skeletal and dental modifications produced by the Bionator III appliance. Am J Orthod Dentofacial Orthop 1998;114:40-44.

15. Loh MK, Kerr WJ. The Function Regulator III: effects and indications for use. Br J Orthod 1985;12:153-157.

16. Almeida MR, Almeida RR, Oltramari-Navarro PV, Conti AC, Navarro R de L, Camacho JG. Early treatment of Class III malocclusion: 10-year clinical follow-up. J Appl Oral Sci 2011;19:431-439.

17. Sugawara J, Asano T, Endo N, Mitani H. Long-term effects of chincup therapy on skeletal profile in mandibular prognathism. Am J Orthod Dentofacial Orthop 1990;98:127-133.

18. Seehra J, Fleming PS, Dibiase AT. Reverse Twin Block appliance for early dental Class III correction. J Clin Orthod 2010;44:602-610;quiz 21.

19. Seehra J, Fleming PS, Mandall N, Dibiase AT. A comparison of two different techniques for early correction of Class III malocclusion. Angle Orthod 2012;82:96-101.

20. Baccetti T, Franchi L, McNamara JA, Jr. Treatment and posttreatment craniofacial changes after rapid maxillary expansion and facemask therapy. Am J Orthod Dentofacial Orthop 2000;118:404-413.

21. Gautam P, Valiathan A, Adhikari R. Skeletal response to maxillary protraction with and without maxillary expansion: a finite element study. Am J Orthod Dentofacial Orthop 2009;135:723-728.

22. Silva Filho 0, Magro A, Capelozza L. Early treatment of Class III malocclusion with rapid maxillary expansion and maxillary protraction. Am J Orthod Dentofacial Orthop 1998;113:196-203.

23. Gautam $P$, Valiathan A, Adhikari R. Maxillary protraction with and without maxillary expansion: a finite element analysis of sutural stresses. Am J Orthod Dentofacial Orthop 2009;136:361-366.

24. Franchi L, Baccetti T, McNamaraJr JA. Postpubertal assessment of treatment timing for maxillary expansion and protraction therapy followed by fixed appliances. Am J Orthod Dentofacial Orthop 2004; 126:555-568

25. Cha BK, Choi DS, Ngan P, Jost-Brinkmann PG, Kim SM, Jang IS. Maxillary protraction with miniplates providing skeletal anchorage in a growing Class III patient. Am J Orthod Dentofacial Orthop 2011;139:99-112.

Received August 10, 2012 Accepted April 2, 2013 